Article

\title{
Fabrication of Cellulose Nanocrystal-g-Poly(Acrylic Acid-Co-Acrylamide) Aerogels for Efficient Pb(II) Removal
}

\author{
Yifan Chen ${ }^{1,2}$, Qian $\mathrm{Li}^{1}{ }^{1}$, Yujie $\mathrm{Li}^{1}{ }^{1}$, Qijun Zhang ${ }^{2}$, Jingda Huang ${ }^{1}$, Qiang $\mathrm{Wu}^{1,2,3, *(1)}$ and \\ Siqun Wang $1,2, *$ (D) \\ 1 School of Engineering, Zhejiang A \& F University, Hangzhou 311300, China; \\ yfchen.28425@foxmail.com (Y.C.); liqian_polymer@126.com (Q.L.); liyujie19971006@163.com (Y.L.); \\ hjd1015@163.com (J.H.) \\ 2 Center for Renewable Carbon, University of Tennessee, Knoxville, TN 37996, USA; qzhang37@vols.utk.edu \\ 3 Zhejiang Provincial Collaborative Innovation Center for Bamboo Resources and High-Efficiency Utilization, \\ Hangzhou 311300, China \\ * Correspondence: wuqiang@zafu.edu.cn (Q.W.); swang@utk.edu (S.W.)
}

Received: 5 December 2019; Accepted: 20 January 2020; Published: 5 February 2020

\begin{abstract}
In this work, cellulose nanocrystals (CNCs) obtained by the acid hydrolysis of waste bamboo powder were used to synthesize cellulose nanocrystal-g-poly(acrylic acid-co-acrylamide) (CNC-g-P(AA/AM)) aerogels via graft copolymerization followed by freeze-drying. The structure and morphology of the resulting aerogels were characterized by Fourier transform infrared spectroscopy (FTIR) and scanning electron microscopy (SEM), and the CNC-g-P(AA/AM) aerogels exhibited excellent absorbent properties and adsorption capacities. Subsequent $\mathrm{Pb}(\mathrm{II})$ adsorption studies showed that the kinetic data followed the pseudo-second-order equation, while the adsorption isotherms were best described using the Langmuir model. The maximum $\mathrm{Pb}(\mathrm{II})$ adsorption capacity calculated by the Langmuir model reached up to $366.3 \mathrm{mg} / \mathrm{g}$, which is a capacity that outperformed that of the pure CNC aerogel. The CNC-g-P (AA/AM) aerogels become structurally stable through chemical cross-linking, which enabled them to be easily regenerated in $\mathrm{HCl}$ solution and retain the adsorption capacity after repeated use. The aerogels were found to maintain $81.3 \%$ removal efficiency after five consecutive adsorption-desorption cycles. Therefore, this study demonstrated an effective method for the fabrication of an aerogel adsorbent with an excellent reusability in the effective removal of $\mathrm{Pb}(\mathrm{II})$ from aqueous solutions.
\end{abstract}

Keywords: cellulose nanocrystal; graft copolymerization; aerogel; adsorption; lead

\section{Introduction}

Over the past few decades, contamination from lead has caused major public health issues due to the widespread usage of this element in many important industries, such as battery manufacturing, electroplating, pigments, and finishing [1,2]. Given the non-biodegradability and cumulative toxicity of lead, this contaminant slowly accumulates in human bodies through water intake or the food chain, ultimately resulting in serious diseases or even death [3,4]. To date, various methods have been applied for the treatment of lead-containing wastewater, including chemical precipitation [5], ion exchange [6], membrane filtration [7], electrochemical technologies [8], and adsorption-based techniques [9,10]. Among them, adsorption is considered to be superior to other technologies due to its ease of operation, high selectivity, high removal efficiency at low concentrations, and lack of secondary pollution [11-14]. In addition, since the quality of the treated water is directly dependent on the properties of the adsorbent, it is of great importance to develop adsorbents that exhibit excellent performances. 
Activated carbon is currently the most widely used adsorbent in the area of heavy metal decontamination. However, its low selectivity and regeneration problems restrict its use [15]. Indeed, activated carbon is not well suited for the treatment of industrial effluents containing low concentrations of $\mathrm{Pb}(\mathrm{II})$, and as such, the development of new high-efficiency adsorbents as an alternative to activated carbon is necessary [16]. Since such adsorbents should be based on readily available and low-cost raw materials, cellulose, the most abundant biopolymer, has attracted increasing attention as a promising adsorbent material due to its renewability and eco-friendly nature.

In recent years, special attention has also been given to nanocellulose. As a cellulose derivative with a large specific surface area, high functionality, light weight, mechanical strength, and tunable surface chemistry, nanocellulose exhibits great potential for application in wastewater decontamination $[17,18]$. Although nanocellulose has a limited adsorption capacity, its structure can be modified or grafted to introduce specific functional groups (e.g., $-\mathrm{COOH},-\mathrm{NH}_{2}$, or $-\mathrm{SO}_{3} \mathrm{H}$ ) that can further enhance its binding efficiency toward pollutants [19-21]. For example, cellulose nanocrystals (CNCs) prepared by acid hydrolysis exhibit a greatly enhanced adsorption capacity following succinic acid modification, giving a maximum adsorption capacity for $\mathrm{Cd}(\mathrm{II})$ of $259.7 \mathrm{mg} / \mathrm{g}$ [22]. In addition, $\mathrm{COO}^{-}$-modified cellulose nanofibers (CNFs) presented a significant enhancement in the adsorption capacities toward $\mathrm{Ni}(\mathrm{II})$ and $\mathrm{Cr}(\mathrm{III})$ as well as $\mathrm{Cd}(\mathrm{II})$ and $\mathrm{Pb}(\mathrm{II})$ compared to unmodified CNFs. Furthermore, thiol-modified nanofibrillated cellulose (NFC) was able to effectively remove $\mathrm{Hg}$ (II) ions over a wide range of concentrations and $\mathrm{pH}$ values [23].

Although modified nanocellulose exhibits an excellent adsorption capacity, some limitations remain. For example, recovery of the nanocellulose is challenging after its use in water treatment processes due to its tendency to agglomerate and also due to its nano-sized dimensions, thereby rendering it unsuitable for direct use as an adsorbent [24]. To address this issue, nanocellulose is often converted into an aerogel or film by appropriate cross-linking [25]. However, the majority of aerogels are prepared using physical interactions, and so the resulting poor chemical stability and low strength in practical applications can also present issues in their application [26].

Thus, to enhance the binding ability of nanocellulose to metal ions, the grafting of commonly used vinyl monomers such as acrylic acid and acrylamide onto the nanocellulose surface results in the introduction of metal-binding carboxyl and amide groups. In addition, a certain degree of wet strength can be obtained via the appropriate cross-linking to achieve desirable separation properties. It should also be noted that since nanocellulose regeneration has received little attention to date, additional studies are required to evaluate the reusability of nanocellulose-based adsorbents.

Thus, we herein report the preparation of CNC-based aerogels exhibiting high adsorption capacities and excellent reusability properties, in which poly(acrylic acid-co-acrylamide) (P(AA/AM)) is grafted onto CNC to increase its adsorption capacity, and $N, N^{\prime}$-methylenebisacrylamide (MBA) is used to cross-link the cellulose nanocrystal-g-poly(acrylic acid-co-acrylamide) (CNC-g-P(AA/AM)) and enhance the wet strength. The CNC used in this study is prepared by sulfuric acid hydrolysis from industrial bamboo waste powder, which was found to have a high surface charge $(-38.7 \mathrm{mV})$, a size of $174 \pm 60 \mathrm{~nm}$ in length and $8.5 \pm 2.5 \mathrm{~nm}$ in diameter, and a sulfonate content $(0.33 \mathrm{mmol} / \mathrm{g})$. The prepared aerogels are then employed in the removal of $\mathrm{Pb}$ (II) from aqueous solution. Furthermore, the data obtained from the adsorption experiments are assessed by various kinetic and isotherm models to study the adsorption mechanism. Finally, the reusability of each CNC-g-P(AA/AM) aerogel is also investigated as an important performance parameter.

\section{Experimental Section}

\subsection{Materials}

Bamboo powder (the CNC raw material) was collected from Hangzhou Bamfox Bamboo Products Co., Ltd. (Hangzhou, China). Sulfuric acid $\left(\mathrm{H}_{2} \mathrm{SO}_{4}, 98\right.$ wt \%) was purchased from Xilong Chemical Co., Ltd. (Yichang, China). Acrylic acid (AA), sodium hypochlorite $\left(\mathrm{NaClO}_{2}\right)$, 
and sodium hydroxide $(\mathrm{NaOH})$ were purchased from Aladdin Chemistry Co., Ltd. (Shanghai, China). Toluene, ethanol, and acetic acid were supplied by Sinopharm Chemical Reagent Company (Shanghai, China). Acrylamide (AM), $N, N^{\prime}$-methylenebisacrylamide (MBA), and potassium persulfate (KPS) were provided by Macklin Biochemical Co., Ltd. (Shanghai, China). All reagents were of analytical grade and were used without any further purification. All aqueous solutions and suspensions were prepared using deionized water.

\subsection{Preparation of the $\mathrm{CNCS}$}

The CNCs were prepared from waste bamboo power according to a previously reported pretreatment and sulfuric acid hydrolysis method [27]. More specifically, the bamboo powder $(30 \mathrm{~g})$ was immersed in a toluene-ethanol solution $(450 \mathrm{~mL}, 2: 1 \mathrm{v} / \mathrm{v})$ for $20 \mathrm{~h}$ under magnetic stirring and then washed with ethanol to remove any wax. Subsequently, the reaction mixture was transferred into a beaker containing a $1.4 \mathrm{wt} \% \mathrm{NaClO}_{2}$ solution $(1000 \mathrm{~mL}, \mathrm{pH} 3-4$, adjusted with acetic acid), and stirred in a water bath at $70^{\circ} \mathrm{C}$ for $5 \mathrm{~h}$ to remove lignin. After this time, the obtained powder was immersed in a $5 \mathrm{wt} \% \mathrm{NaOH}$ solution $(600 \mathrm{~mL})$ and stirred at $90^{\circ} \mathrm{C}$ for $4 \mathrm{~h}$ to remove the hemicellulose and obtain the bamboo cellulose. For preparation of the CNC suspensions, the bamboo cellulose was hydrolyzed using a $65 \mathrm{wt} \%$ sulfuric acid solution $\left(10 \mathrm{~mL} \mathrm{~g}^{-1}\right)$ at $45^{\circ} \mathrm{C}$ under constant mechanical stirring, and the reaction was stopped by diluting with 10 times the volume of ice water. The resulting suspension was subjected to centrifugation, and then dialyzed until a neutral $\mathrm{pH}$ was achieved. Finally, the suspension was subjected to ultrasonication using an ultrasonic processor (JY98-IIID Ningbo Scientz Biotechnology Co., Ltd., Ningbo, China) in an ice bath to obtain a uniformly dispersed CNC suspension.

\subsection{Synthesis of the CNC-g-P(AA/AM) Aerogels}

The CNC-g-P(AA/AM) aerogels were synthesized by grafting the CNCs with AA and AM and cross-linking with MBA, as depicted in Figure 1. Initially, different weights of the CNC slurry (3.0, 6.0, or $12.0 \mathrm{~g}$ by dry weight) were added to water (total $150 \mathrm{~g}$ suspension) under continuous stirring followed by ultrasonication for $10 \mathrm{~min}$. Then, each resulting suspension was added to a separate three-necked flask equipped with an electric stirrer, and nitrogen gas was bubbled through the suspensions for $30 \mathrm{~min}$ to remove any dissolved oxygen. After this time, KPS (0.04 g) dissolved in deionized water $(5 \mathrm{~g})$ was added to each suspension, and the resulting mixtures were maintained at $60^{\circ} \mathrm{C}$ for $10 \mathrm{~min}$. AA $(3 \mathrm{~g})$, AM ( $3 \mathrm{~g})$, and MBA $(0.08 \mathrm{~g})$ dissolved in water $(50 \mathrm{~g})$ were added to the above flasks and maintained under the same condition for a further $120 \mathrm{~min}$ to the obtain gel samples. Then, the resulting gels were neutralized by titration with sodium hydroxide solution washed with deionized water to remove any residual impurities. Finally, the samples were freeze-dried to obtain the desired aerogels, which were named based on the mass ratio of CNC to the total of AA and AM, namely CNC-g-P(AA/AM)-0.5, CNC-g-P(AA/AM)-1, and CNC-g-P(AA/AM)-2. P(AA/AM) without the addition of $\mathrm{CNC}$ was prepared in the same manner as a control group to investigate the effect of the addition of $\mathrm{CNC}$ on the swelling behavior of the aerogel. For a comparison of the adsorption performance, CNC was prepared into $2 \mathrm{wt} \%$ suspension and then freeze-dried to obtain CNC aerogel.

\subsection{Characterization}

\subsubsection{Fourier Transform Infrared (FTIR) Spectroscopy}

Fourier transform infrared (FTIR) spectroscopy (Nicolet 6700, Thermofisher, Waltham, MA, USA) was used to identify the functional groups present on the $\mathrm{CNC}$ and the aerogels. The thoroughly dried aerogels were analyzed following careful grinding with $\mathrm{KBr}(1: 200, \mathrm{w} / \mathrm{w})$ and pressing into transparent pellets. Spectra were collected 32 times in the range $4000-500 \mathrm{~cm}^{-1}$ with a wavenumber resolution of $4 \mathrm{~cm}^{-1}$. 


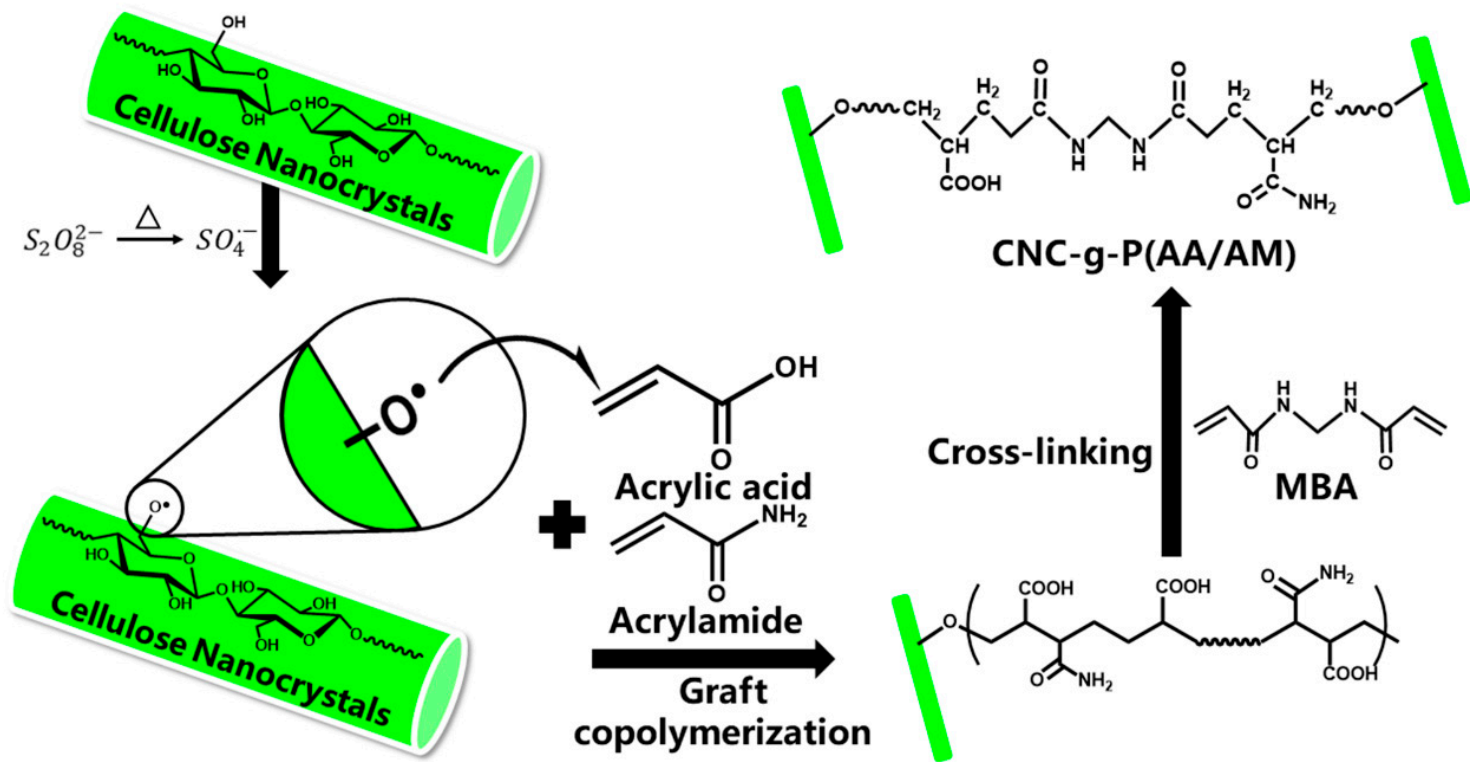

Figure 1. Mechanism of cellulose nanocrystal-g-poly(acrylic acid-co-acrylamide) (CNC-g-P(AA/AM)) aerogel preparation.

\subsubsection{Scanning Electron Microscopy (SEM)}

The aerogel samples were observed by SEM, (TM3030, Tokyo, Japan) at an accelerating voltage of $15 \mathrm{kV}$. Prior to carrying out any observations, the aerogel surfaces were sputter-coated with a thin film of gold by an ion sputter (MC1000, Hitachi, Tokyo, Japan).

\subsubsection{Swelling Capacity and Kinetics}

The dried sample $(0.2 \mathrm{~g})$ was fully immersed in excessive deionized water at $293 \mathrm{~K}$ until the swelling equilibrium was reached. At predetermined time intervals, samples were removed from the water and weighed after removing any water on the sample surface by wiping with wet filter paper. The swelling ratio (SR) was calculated according to Equation (1):

$$
\mathrm{SR}=\left(W_{S}-W_{d}\right) / W_{d}
$$

where $W_{s}$ is the weight of the swollen aerogel and $W_{d}$ is the weight of the dry aerogel.

\subsubsection{Adsorption Studies}

Adsorption experiments were conducted using the batch method to examine the adsorption kinetics and adsorption isotherms for the adsorption of $\mathrm{Pb}$ (II) by the CNC-g-P(AA/AM) aerogels. The adsorption kinetics were tested at $293 \mathrm{~K}$ by adding the dried sample $(0.10 \mathrm{~g})$ into the $\mathrm{Pb}$ (II) solution $(100 \mathrm{~mL})$ with a shaking rate of $150 \mathrm{rpm}$, where an initial $\mathrm{Pb}$ (II) concentration of $200 \mathrm{ppm}$ was employed to reach the adsorption equilibrium. The variation in the concentration of $\mathrm{Pb}$ (II) was measured by an inductively coupled plasma optical emission spectrometer (NexION 1000, PerkinElmer, Fremont, CA, USA). The pseudo-first [28] and pseudo-second-order kinetic models [29] as well as the intraparticle diffusion model were used to determine the rate constant and to analyze the mechanism of the adsorption process:

$$
\begin{aligned}
\ln \left(q_{e}-q_{t}\right) & =\ln q_{e}-k_{1} t / 2.303 \\
\frac{t}{q_{t}} & =\frac{1}{k_{2} q_{e}^{2}}+\frac{t}{q_{e}}
\end{aligned}
$$


where $q_{t}\left(\mathrm{mg} \mathrm{g}^{-1}\right)$ and $q_{e}\left(\mathrm{mg} \mathrm{g}^{-1}\right)$ are the amount of metal adsorbed at time $t$ and at equilibrium, respectively, and $k_{1}\left(\mathrm{~min}^{-1}\right)$ and $k_{2}\left(\mathrm{~g} \mathrm{mg}^{-1} \cdot \mathrm{min}^{-1}\right)$ are the rate constants of the pseudo-first and pseudo-second order models, respectively.

Furthermore, the intra-particle diffusion model was also used to determine the mechanism of $\mathrm{CNC}-\mathrm{g}-\mathrm{P}(\mathrm{AA} / \mathrm{AM})$ aerogels for $\mathrm{Pb}(\mathrm{II})$ removal in view of diffusion.

$$
q_{t}=k_{i} t^{1 / 2}+C
$$

where $k_{i}$ is the intra-particle diffusion rate constant $\left(\mathrm{mg} \mathrm{g}^{-1} \min ^{1 / 2}\right)$ and $C$ is a constant related to the boundary layer effect.

The Langmuir and Freundlich isotherm models are the most widely used sorption isotherms for examining the removal of metal ions from an aqueous solution. Therefore, they were employed here to evaluate the adsorption mechanism and to investigate the adsorption capacities of the adsorbents. The linear forms of the isotherm models are represented by Equations (5) and (6) [30,31]:

$$
\begin{gathered}
\frac{C_{e}}{Q_{e}}=\frac{C_{e}}{Q_{m}}+\frac{1}{Q_{m} b} \\
\lg Q_{e}=\lg k_{f}+\lg C_{e} / n
\end{gathered}
$$

where $Q_{e}\left(\mathrm{mg} \mathrm{g}^{-1}\right)$ is the equilibrium adsorption capacity, $C_{e}\left(\mathrm{mg} \mathrm{L}^{-1}\right)$ is the equilibrium concentration of $\mathrm{Pb}(\mathrm{II}), Q_{m}\left(\mathrm{mg} \mathrm{g}^{-1}\right)$ is the maximum adsorption capacity, $b\left(\mathrm{~L} \mathrm{mg}^{-1}\right)$ is the Langmuir adsorption constant related to the energy of adsorption, and $k_{f}$ and $n$ are the Freundlich adsorption constants that indicate the capacity and intensity of the adsorption, respectively.

\section{Results and Discussion}

\subsection{Syntheses and Characterization of the CNC-g-P(AA/AM) Aerogels}

The CNC-g-P(AA/AM) aerogels were prepared by free radical graft polymerization. During this process, the KPS initiator was firstly decomposed into sulfate anion radicals under heating. Then, the hydrogen atoms from the hydroxyl groups were trapped by these radicals to form alkoxy radicals on the CNC surface. Due to the functional group activity and steric effects, the primary hydroxyl groups present on $\mathrm{CNC}$ are more prone to attack by sulfate anion radicals than secondary hydroxyl groups [32]. With the introduction of monomer molecules (AA and AM) into the system, the active radical sites on $\mathrm{CNC}$ would initiate chain propagation in the monomer vinyl groups, thereby resulting in cross-linking reactions taking place simultaneously, and the MBA becoming connected to the polymer chains by covalent bonds to form a three-dimensional network. Finally, the samples were freeze-dried to obtain the desired CNC-g-P(AA/AM) aerogels. It should be noted here that chemical cross-linking is known to provide a certain degree of wet strength to aerogels, thereby preventing their collapse in water. According to the mass-volume method, the density of the resulting aerogels was measured as 11.2, 139.6, 85.3, and $55.2 \mathrm{mg} / \mathrm{cm}^{3}$ for CNC aerogel, CNC-g-P(AA-AM)-0.5, CNC-g-P(AA-AM)-1, and CNC-g-P(AA-AM)-2, respectively. To determine the structures of the prepared aerogels, characterization by FTIR and SEM was carried out.

To confirm the successful grafting of the $\mathrm{P}(\mathrm{AA} / \mathrm{AM})$ chains onto the $\mathrm{CNC}$ surface, the functional groups of dry $\mathrm{P}(\mathrm{AA} / \mathrm{AM})$, the $\mathrm{CNC}-\mathrm{g}-\mathrm{P}(\mathrm{AA} / \mathrm{AM})$ aerogels, and the $\mathrm{CNC}$ aerogel were examined by FTIR, as outlined in Figure 2. The characteristic peaks observed in the CNC spectra at 3345 and $2904 \mathrm{~cm}^{-1}$ correspond to the $\mathrm{O}-\mathrm{H}$ stretching and asymmetric $\mathrm{C}-\mathrm{H}$ stretching, respectively. Meanwhile, the peaks at 1160 and $1060 \mathrm{~cm}^{-1}$ represent $\mathrm{C}-\mathrm{O}$ and $\mathrm{C}-\mathrm{O}-\mathrm{C}$ stretching [33]; these signals are not observed in the spectra of $\mathrm{P}(\mathrm{AA} / \mathrm{AM})$; therefore, their intensities reflect the $\mathrm{CNC}$ content. Furthermore, the $\mathrm{C}=\mathrm{O}$ symmetric stretching vibration was observed at 1667 and $1451 \mathrm{~cm}^{-1}$ in the CNC-g-P(AA/AM) aerogel spectra, thereby confirming that AA and AM were successfully grafted onto the CNC surface $[34,35]$. Moreover, the bonding and bending vibration of $\mathrm{N}-\mathrm{H}$ observed at $1566 \mathrm{~cm}^{-1}$ was attributed to the 
successful graft polymerization of the AM monomer. Shifting of the hydroxyl group peak from 3345 to $3445 \mathrm{~cm}^{-1}$ was attributed to the overlapping and intermolecular association of the $\mathrm{O}-\mathrm{H}$ and $\mathrm{N}-\mathrm{H}$ groups [36]. The signal peaks of $\mathrm{O}-\mathrm{H}$ of carboxylic acid over $1700 \mathrm{~cm}^{-1}$ are not found in the FTIR spectra of CNC-g-P(AA/AM) aerogels due to the neutralization, but that of the carbonyl group of the carboxylate can be found at $1400 \mathrm{~cm}^{-1}$. Compared with the raw $\mathrm{CNC}$, the peak corresponding to the $\mathrm{C}-\mathrm{H}$ stretching vibration shifted from 2904 to $2928 \mathrm{~cm}^{-1}$ in the spectra of the CNC-g-P(AA/AM) aerogels, and it was interesting to note that the intensity of the peak attributed to the $\mathrm{C}-\mathrm{O}$ and $\mathrm{C}-\mathrm{O}-\mathrm{C}$ stretching groups at $1060 \mathrm{~cm}^{-1}$ based on the normalized spectra was found to decrease upon decreasing the CNC content. This further confirmed that the P(AA/AM) was successfully grafted onto the CNC surface.

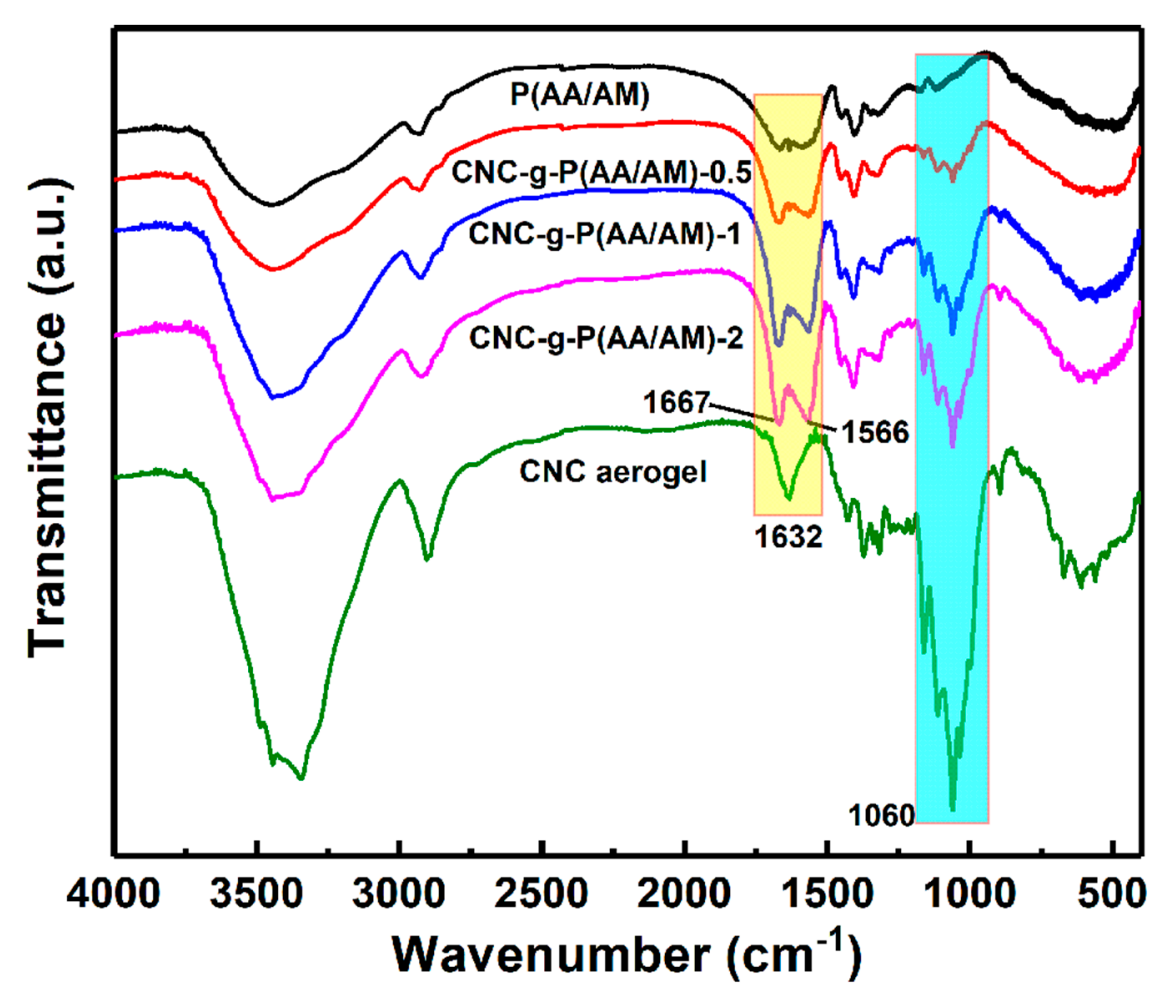

Figure 2. Fourier transform infrared spectroscopy (FTIR) spectra of the poly(acrylic acid-co-acrylamide) (P(AA/AM)), CNC-g-P(AA/AM)-0.5, CNC-g-P(AA/AM)-1, CNC-g-P(AA/AM)-2, and CNC aerogel.

The microstructure of the adsorbent is known to have a major impact on its adsorption performance. The TEM image of CNCs and SEM images of CNC aerogel, P(AA/AM), and CNC-g-P(AA/AM) aerogels are shown in Figure 3. As shown in Figure 3a, CNCs extracted from waste bamboo powder have good dispersibility, and needle-shaped fibers can be observed in the SEM image of CNC aerogel (Figure 3b). As for the chemical cross-linked aerogel, $\mathrm{P}(\mathrm{AA} / \mathrm{AM})$ possesses an open and macroporous honeycomb structure, and comparison of the recorded SEM images shows that the pores of the aerogel become smaller upon increasing the CNC loading. This is because the addition of CNCs increased the effective cross-link density of aerogels and then led to an increase in the porosity of the aerogel, which may contribute to an increased specific surface. 

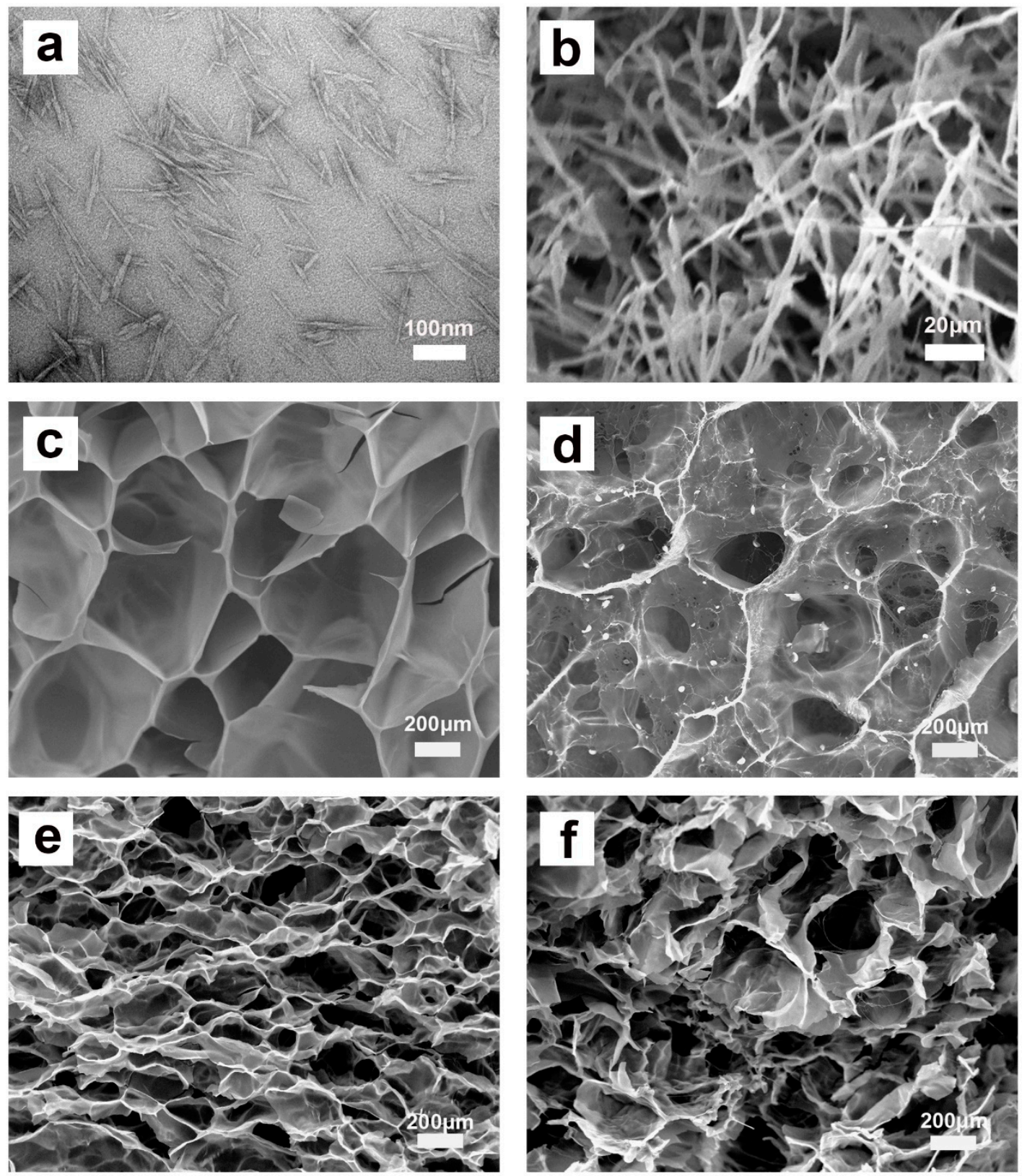

Figure 3. TEM image of CNCs (a) and SEM images of CNC aerogel (b), P(AA/AM) (c), CNC-g-P(AA/AM)-0.5 (d), CNC-g-P(AA/AM)-1 (e), and CNC-g-P(AA/AM)-2 (f).

\subsection{Swelling Behavior}

The water absorbency capacity is an important parameter for evaluating gel materials since it is key to their application [37]. In the context of this study, CNC-g-P (AA/AM) aerogels have shown their ability to swell in water by absorbing water into their porous three-dimensional networks, while $\mathrm{CNC}$ aerogel does not. Therefore, the swelling properties of $\mathrm{P}(\mathrm{AA} / \mathrm{AM}), \mathrm{CNC}-\mathrm{g}-\mathrm{P}(\mathrm{AA} / \mathrm{AM})-0.5$, CNC-g-P(AA/AM)-1, and CNC-g-P(AA/AM)-2 were examined and the results are presented in Figure 4. As shown, all aerogels exhibited a rapid water absorption behavior following immersion in water, and a time of approximately $3 \mathrm{~h}$ was required to attain the swelling equilibrium. Among the various aerogels examined herein, the swelling rate and swelling ratio of the $\mathrm{P}(\mathrm{AA} / \mathrm{AM})$ aerogel was significantly greater than that of the $\mathrm{CNC}-\mathrm{g}-\mathrm{P}(\mathrm{AA} / \mathrm{AM})$ aerogels. In addition, the maximum water absorption ratio of $\mathrm{P}(\mathrm{AA} / \mathrm{AM})$ reached $621 \mathrm{c}$, while that of the other three CNC-g-P(AA/AM) aerogels was 553, 417, 
and $286 \mathrm{~g} \mathrm{~g}^{-1}$, respectively. This is because the addition of CNC leads to a shrinkage of the aerogel pores, which slows the entry of water, and it is also consistent with the results observed by SEM.

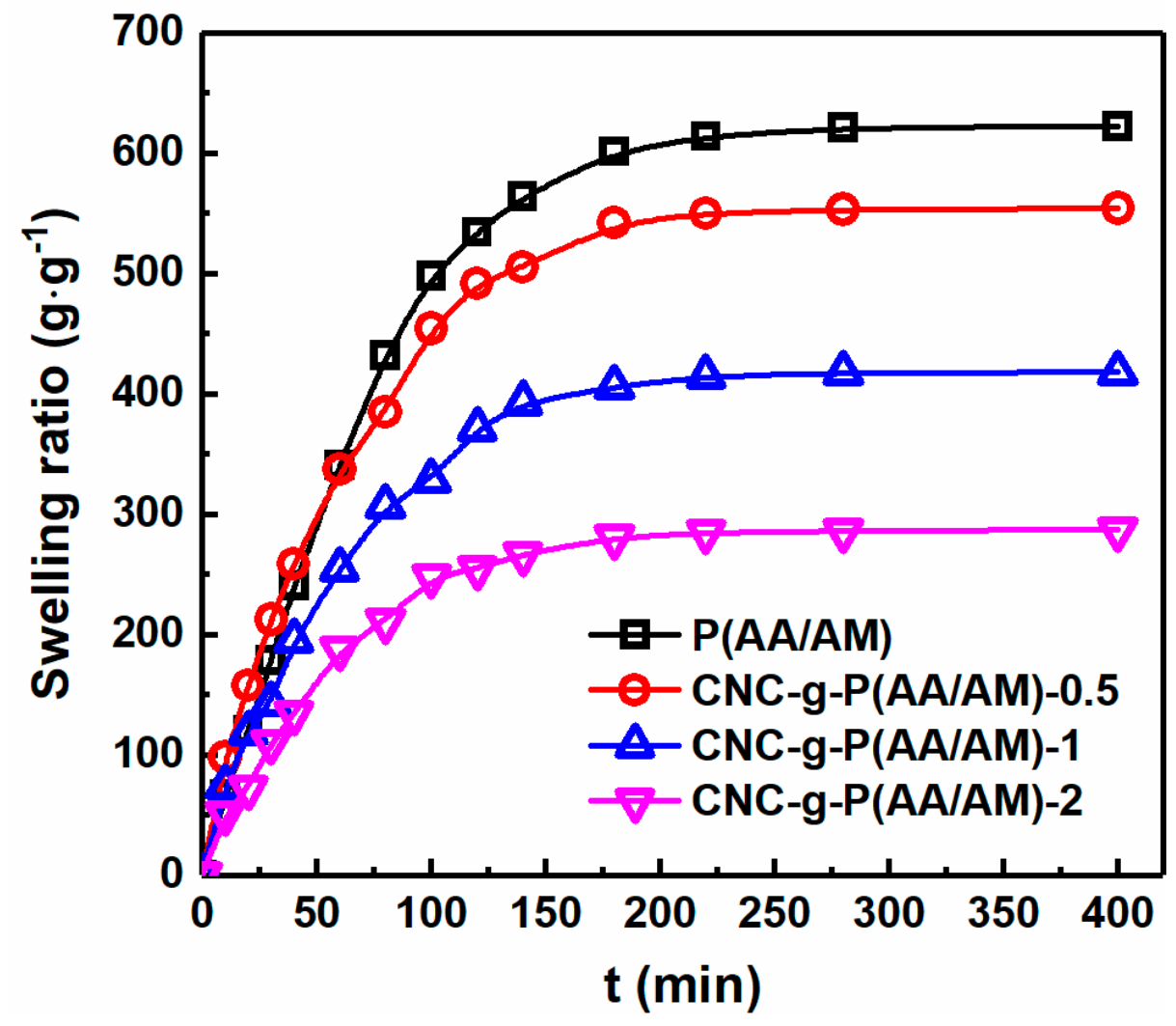

Figure 4. Swelling ratios of $\mathrm{P}(\mathrm{AA} / \mathrm{AM})$, CNC-g-P(AA/AM)-0.5, CNC-g-P(AA/AM)-1, and CNC-g$\mathrm{P}(\mathrm{AA} / \mathrm{AM})-2$.

\subsection{Adsorption Performance}

Then, the adsorption kinetics of the CNC-g-P(AA/AM) aerogels were investigated to determine the adsorption rate and eventually explore the adsorption mechanism involved. Since most heavy metals are often present in the form of divalent cations, and lead is the most common one, it is selected as the adsorption target. Thus, Figure 5a shows the variation in adsorption performance with respect to the contact time at an initial $\mathrm{Pb}$ (II) concentration of $200 \mathrm{ppm}$. As indicated, the CNC aerogel exhibited a high adsorption rate at the initial adsorption stage and reached the adsorption equilibrium rapidly with a final removal efficiency of $74.6 \%$. In contrast, although the removal rates of the $\mathrm{CNC}-\mathrm{g}-\mathrm{P}(\mathrm{AA} / \mathrm{AM})$ aerogels also increased rapidly during the initial stage, further increases were relatively slow, and equilibrium was finally reached after approximately $120 \mathrm{~min}$. Impressively, the removal efficiencies of all the CNC-g-P(AA/AM) aerogels were $>90 \%$. Due to the porous structures of the aerogels and the presence of hydroxyl and sulfonic acid groups, $\mathrm{Pb}$ (II) can be rapidly absorbed by the aerogels in the initial stage. In addition, the presence of carboxylic acid and amino moieties led to a greater quantity of $\mathrm{Pb}$ (II) being adsorbed by the $\mathrm{CNC}-\mathrm{g}-\mathrm{P}(\mathrm{AA} / \mathrm{AM})$ aerogels, thereby yielding significantly improved removal efficiencies compared to CNC itself. 

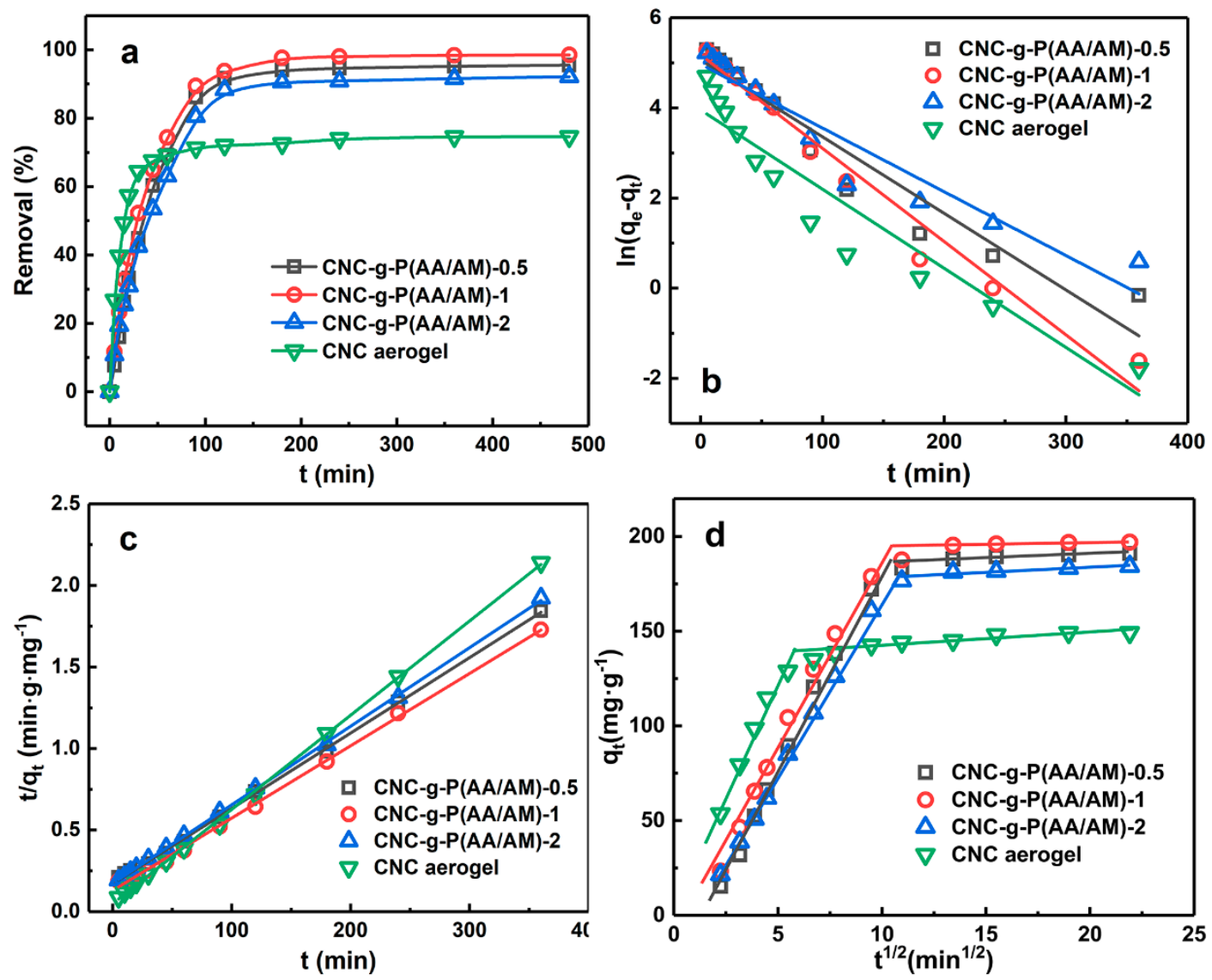

Figure 5. Kinetic studies of $\mathrm{Pb}(\mathrm{II})$ adsorption by the CNC-g-P(AA/AM)-0.5, CNC-g-P(AA/AM)-1, CNC-g-P(AA/AM)-2, and CNC aerogels $\left(\mathrm{C}_{0}=200 \mathrm{mg} \mathrm{L}^{-1}\right)$. (a) Effect of contact time, (b) the pseudo-first-order, (c) the pseudo-second-order, and (d) intra-particle diffusion models.

\subsubsection{Adsorption Kinetics}

To further analyze the adsorption process, the pseudo-first-order and pseudo-second-order kinetic models were used to investigate the adsorption kinetics (Figure $5 b, c$ ). The adsorption data in Figure $5 a$ were fitted linearly using Equations (2) and (3), and the related kinetic parameters are summarized in Table 1. Among them, the coefficient of determination $\left(R^{2}\right)$ of kinetic models was used to analyze the fitting degrees with experimental data [38]. Thereby, the pseudo-second-order model better describes the adsorption kinetics of $\mathrm{Pb}$ (II) on the aerogels than the pseudo-first-order model [39]. In addition, the theoretical $\mathrm{q}_{\mathrm{e} 2 \text {,cal }}$ calculated from the pseudo-second-order model agreed well with the experimentally-obtained equilibrium $\mathrm{Pb}$ (II) absorption $\left(\mathrm{q}_{\mathrm{e}, \mathrm{exp}}\right)$, as outlined in Table 2 . This also suggests that the adsorption reaction of $\mathrm{Pb}(\mathrm{II})$ was a chemical process controlled by chemisorption behavior [40].

Table 1. Kinetic parameters for $\mathrm{Pb}(\mathrm{II})$ adsorption on the CNC-g-P(AA/AM)-0.5, CNC-g-P(AA/AM)-1, CNC-g-P(AA/AM)-2, and CNC aerogels.

\begin{tabular}{|c|c|c|c|c|c|c|c|}
\hline \multirow[b]{2}{*}{ Sample } & \multirow[b]{2}{*}{$Q_{e, \exp }\left(m g g^{-1}\right)$} & \multicolumn{3}{|c|}{ Pseudo-First-Order } & \multicolumn{3}{|c|}{ Pseudo-Second-Order } \\
\hline & & $\begin{array}{c}\mathrm{k}_{1} \times 10^{-3} \\
\left(\min ^{-1}\right)\end{array}$ & $\begin{array}{c}\mathrm{q}_{\mathrm{e} 1, \mathrm{cal}} \\
\left(\mathrm{mg} \mathrm{g}^{-1}\right)\end{array}$ & $\mathbf{R}^{2}$ & $\begin{array}{l}\mathrm{k}_{2} \times 10^{-4}(\mathrm{~g} \\
\left.\mathrm{mg}^{-1} \min ^{-1}\right)\end{array}$ & $\begin{array}{c}\mathrm{q}_{\mathrm{e} 2, \mathrm{cal}} \\
\left(\mathrm{mg} \mathrm{g}^{-1}\right)\end{array}$ & $\mathbf{R}^{2}$ \\
\hline CNC aerogel & 169.6 & 7.60 & 52.16 & 0.906 & 6.19 & 173.0 & 0.992 \\
\hline CNC-g-P(AA/AM)-0.5 & 217.3 & 7.34 & 157.4 & 0.933 & 1.10 & 220.3 & 0.995 \\
\hline CNC-g-P(AA/AM)-1 & 223.8 & 8.94 & 176.5 & 0.975 & 1.51 & 225.7 & 0.998 \\
\hline CNC-g-P(AA/AM)-2 & 210.8 & 6.12 & 143.8 & 0.924 & 1.35 & 207.5 & 0.999 \\
\hline
\end{tabular}


Table 2. Kinetic parameters of the intra-particle diffusion model.

\begin{tabular}{cccccc}
\hline Parameters & $\begin{array}{c}\text { CNC-g- } \\
\text { P(AA/AM)-0.5 }\end{array}$ & $\begin{array}{c}\text { CNC-g- } \\
\text { P(AA/AM)-1 }\end{array}$ & $\begin{array}{c}\text { CNC-g- } \\
\text { P(AA/AM)-2 }\end{array}$ & CNC Aerogel \\
\hline Stage 1 & $\mathrm{R}^{2}$ & 0.985 & 0.978 & 0.999 & 0.981 \\
\hline & $\mathrm{k}_{\mathrm{i}, 1}\left(\mathrm{mg} \mathrm{g}^{-1} \mathrm{~min}^{1 / 2}\right)$ & 20.35 & 19.53 & 19.31 & 23.72 \\
\hline Stage 2 & $\mathrm{C}\left(\mathrm{mg} \mathrm{g}^{-1}\right)$ & -25.65 & -10.46 & -22.69 & 3.831 \\
\hline & $\mathrm{R}^{2}$ & 0.972 & 0.928 & 0.991 & 0.914 \\
\hline & $\mathrm{k}_{\mathrm{i}, 2}\left(\mathrm{mg} \mathrm{g}^{-1} \mathrm{~min}^{1 / 2}\right)$ & 0.338 & 0.194 & 0.372 & 0.718 \\
\hline & $\mathrm{C}\left(\mathrm{mg} \mathrm{g}^{-1}\right)$ & 183.81 & 192.96 & 176.14 & 135.18 \\
\hline
\end{tabular}

The intra-particle diffusion model further reveals the adsorption mechanism of aerogel on $\mathrm{Pb}$ (II) from the perspective of ion diffusion. As shown in Figure $5 \mathrm{~d}$ and Table 2, all the plots did not pass through the origin $(0,0)$ and include two linear segments, which indicated that the adsorption might be controlled by more than one adsorption mechanism. The first stage is the transport of $\mathrm{Pb}$ (II) from the solution to the aerogel external surface, and the second stage is when $\mathrm{Pb}$ (II) enters the interior of the aerogel by diffusion and combines with the active sites on the adsorbent [41]. Moreover, at the first stage, $\mathrm{k}_{\mathrm{i}}$ of $\mathrm{CNC}$ aerogel was the highest, which suggested that $\mathrm{Pb}(\mathrm{II})$ are more likely to enter its interior. Since CNC-g-P(AA/AM) aerogels have 3D cellular structures, $\mathrm{Pb}$ (II) has to enter the interior of them through pores, which led to the $\mathrm{CNC}$ aerogel having a faster adsorption rate than them.

\subsubsection{Adsorption Isotherms}

To further explain the adsorption mechanism, the Langmuir and Freundlich isotherm models were employed; the adsorption isotherm parameters and corresponding plots are displayed in Figure 6 and Table 3, respectively. The higher correlation coefficient obtained for the Langmuir model illustrated that the experimental data fit the Langmuir model $\left(R^{2}>0.99\right)$ to a greater extent than the Freundlich model [42]. Based on these results, it can be deduced that the adsorption process involves Langmuir monolayer adsorption, which was likely due to electrostatic attractions between the carboxyl groups and $\mathrm{Pb}(\mathrm{II})$, in addition to chelation between the amine groups and the metal ions [43]. Among the three aerogels, CNC-g-P(AA/AM)-1 exhibited the highest adsorption capacity with a theoretical maximum adsorption capacity of $366.3 \mathrm{mg} \mathrm{g}^{-1}$.
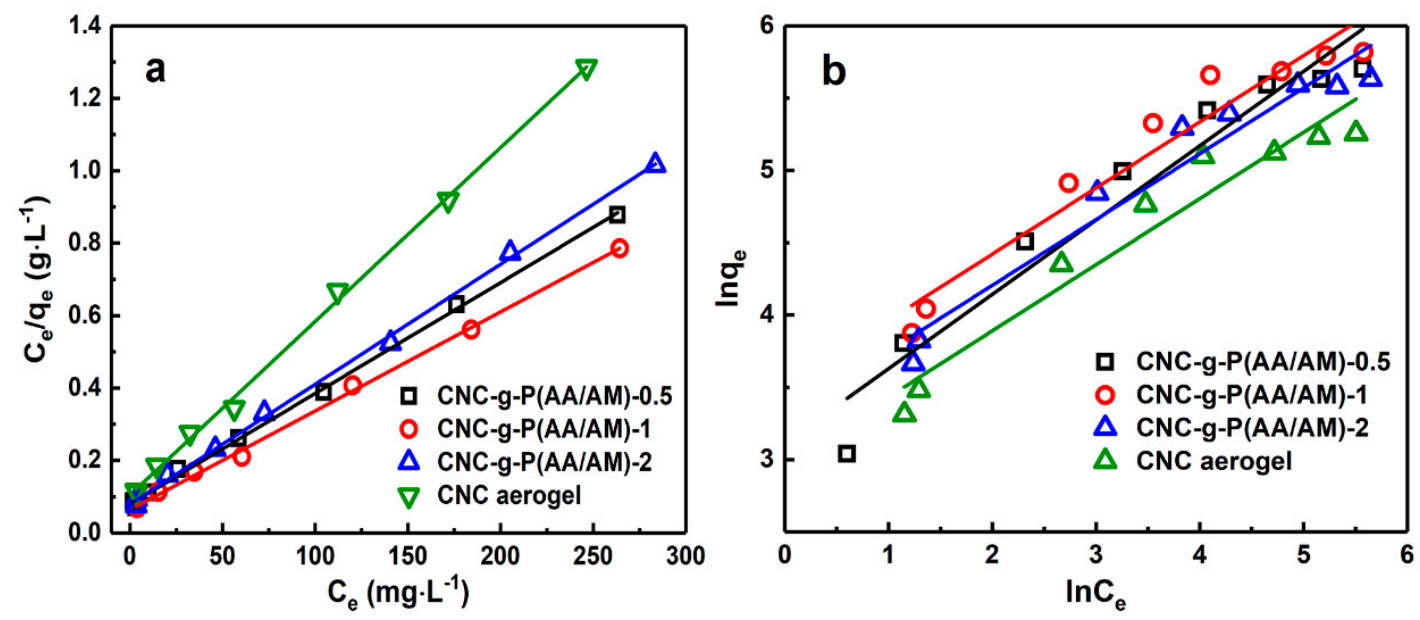

Figure 6. Comparison of the adsorption isotherm models for $\mathrm{Pb}(\mathrm{II})$ adsorption on the $\mathrm{CNC}$-g$\mathrm{P}(\mathrm{AA} / \mathrm{AM})-0.5$, CNC-g-P(AA/AM)-1, CNC-g-P(AA/AM)-2, and CNC aerogels. The (a) Langmuir and (b) Freundlich models. 
Table 3. Adsorption isotherm parameters for the Langmuir and Freundlich models.

\begin{tabular}{ccccccc}
\hline \multirow{2}{*}{ Sample } & \multicolumn{3}{c}{ Langmuir Model } & \multicolumn{3}{c}{ Freundlich Model } \\
\cline { 2 - 7 } & $\boldsymbol{Q}_{\boldsymbol{m}} \mathbf{( m g ~ g - 1}^{\mathbf{1}} \mathbf{)}$ & $\boldsymbol{b}$ & $\mathbf{R}^{\mathbf{2}}$ & $\boldsymbol{n}$ & $\boldsymbol{k}_{f}$ & $\mathbf{R}^{\mathbf{2}}$ \\
\hline CNC aerogel & 208.3 & 0.046 & 0.998 & 2.19 & 19.6 & 0.934 \\
CNC-g-P(AA/AM)-0.5 & 326.8 & 0.026 & 0.998 & 1.95 & 22.5 & 0.933 \\
CNC-g-P(AA/AM)-1 & 366.3 & 0.060 & 0.998 & 2.19 & 33.3 & 0.933 \\
CNC-g-P(AA/AM)-2 & 302.1 & 0.024 & 0.998 & 2.20 & 27.0 & 0.939 \\
\hline
\end{tabular}

\subsection{Effect of Solution $p H$}

The $\mathrm{pH}$ of the solution has also been considered to have an important influence on the metal ion adsorption process. Thus, using the CNC-g-P(AA/AM)- 1 aerogel, the effect of the $\mathrm{pH}$ value (i.e., $\mathrm{pH}=2-6$ ) on its removal of $\mathrm{Pb}(\mathrm{II})$ was investigated. As outlined in Figure 7, an extremely low removal rate was obtained at $\mathrm{pH}=2.0$. Upon increasing the $\mathrm{pH}$ value, the removal efficiency increased significantly due to swelling of the aerogel and increased interactions between the aerogel and $\mathrm{Pb}(\mathrm{II})$. This can be accounted for by the fact that the amine and carboxyl groups are prone to protonation at lower $\mathrm{pH}$ values [44], thereby resulting in reduced electrostatic attraction to the positively charged $\mathrm{Pb}$ (II) ions. In addition, an excess of hydrogen ions reduces carboxyl ionization, leading to competition for the adsorption site. Therefore, the optimum $\mathrm{pH}$ range for $\mathrm{Pb}(\mathrm{II})$ removal was determined to be between $\mathrm{pH}=4-6$.

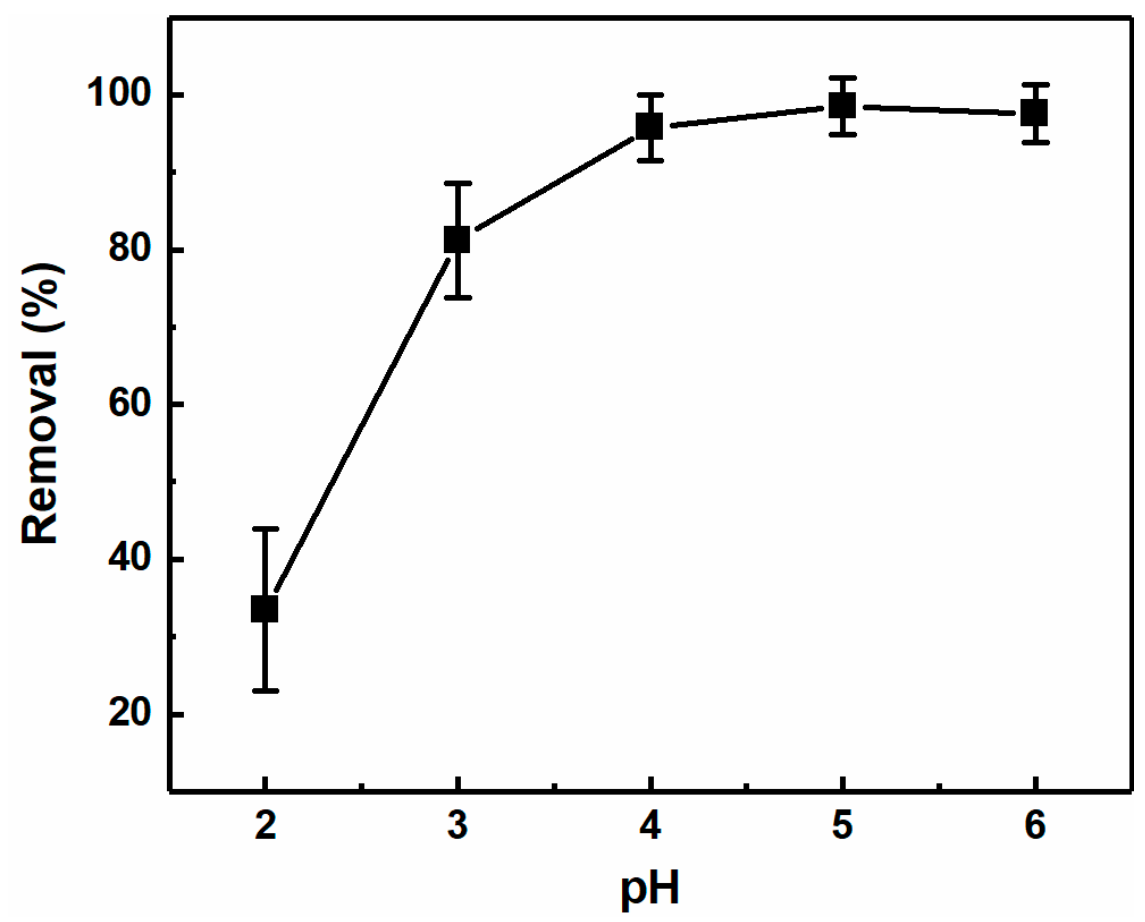

Figure 7. Effect of $\mathrm{pH}$ on the $\mathrm{Pb}(\mathrm{II})$ removal efficiency of $\mathrm{CNC}-\mathrm{g}-\mathrm{P}(\mathrm{AA}-\mathrm{AM})-1\left(\mathrm{C}_{0}=200 \mathrm{mg} \mathrm{L}{ }^{-1}\right)$.

\subsection{Reusability}

Reusability is also an important factor for evaluating the performance of adsorbents in practical application. Thus, to regenerate the aerogels following adsorption, they were immersed in a $0.1 \mathrm{~mol} \mathrm{~L}^{-1}$ $\mathrm{HCl}$ solution, washed with deionized water, and employed in the subsequent adsorption cycles. As shown in Figure 8, after five adsorption-desorption cycles, the adsorption capacity of the CNC-g-P(AA/AM)-1 aerogel decreased slightly but remained at $81.3 \%$. This demonstrated that the $\mathrm{CNC}-\mathrm{g}-\mathrm{P}(\mathrm{AA} / \mathrm{AM})-1$ aerogels exhibit excellent reusability properties. It is likely that the decrease in 
adsorption capacity was caused by the irreversible binding of $\mathrm{Pb}(\mathrm{II})$ to the active sites and protonation of the functional groups during the regeneration process.

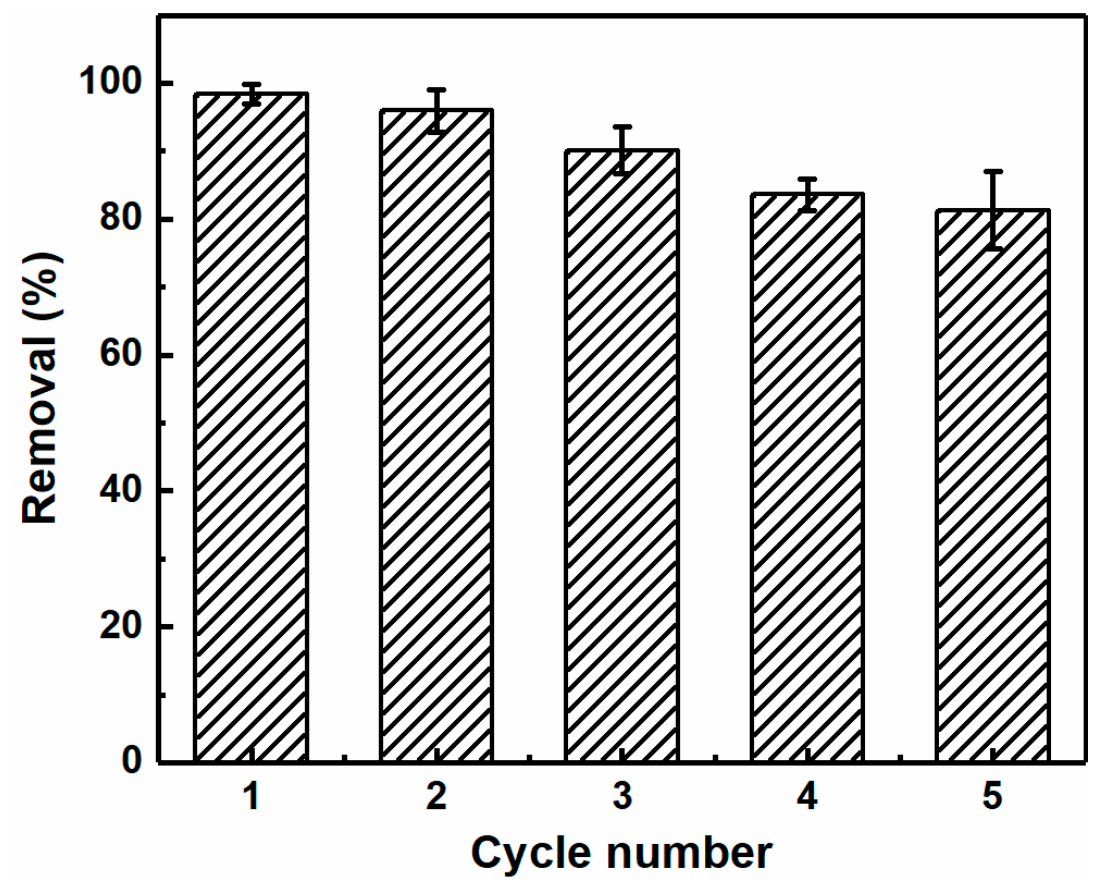

Figure 8. The removal efficiency of $\mathrm{Pb}(\mathrm{II})$ by $\mathrm{CNC}-\mathrm{g}-\mathrm{P}(\mathrm{AA} / \mathrm{AM})-1$ over five adsorptiondesorption cycles.

Nowadays, nanocellulose-based adsorbents are of great interest. However, nanocellulose must be modified to achieve excellent adsorption capacity. The aerogels prepared in this work have shown better adsorption capacity than the nanocellulose-based adsorbents in many literatures [45-47]. Considering the excellent recyclability of $\mathrm{CNC}-\mathrm{g}-\mathrm{P}(\mathrm{AA} / \mathrm{AM})$ aerogels, they are more competitive for practical use than many other nanocellulose-based adsorbents.

\section{Conclusions}

In this article, the CNCs extracted from waste bamboo powder using acid hydrolysis were demonstrated to be an effective adsorbent for removal of $\mathrm{Pb}$ (II) from aqueous solution and used to synthesize $\mathrm{CNC}-\mathrm{g}-\mathrm{P}(\mathrm{AA} / \mathrm{AM})$ aerogels. The resulting aerogels exhibited excellent adsorption capabilities. Indeed, a theoretical maximum adsorption capacity of CNC-g-P(AA/AM) aerogels toward $\mathrm{Pb}$ (II) reached $366.30 \mathrm{mg} / \mathrm{g}$, and this value is significantly higher than that of CNC alone, which is likely due to the structural modification and functionalization carried out herein. In addition, the pseudo-second-order and Langmuir models were found to best describe the kinetics and equilibrium data, respectively. The effects of CNCs dosage on the adsorption properties of CNC-g-P(AA/AM) aerogels were also systematically studied. Furthermore, CNC-g-P(AA/AM) aerogels could be regenerated by immersion in $0.1 \mathrm{~mol} \mathrm{~L}^{-1} \mathrm{HCl}$ solution, and an $81.3 \%$ removal efficiency was maintained after five consecutive adsorption-desorption cycles.

Author Contributions: Conceptualization, Q.W. and S.W.; methodology and investigation, Y.C., Y.L., Q.Z. and J.H.; writing-original draft preparation, Y.C. and Q.L.; writing-review and editing, Q.W. and S.W. All authors have read and agreed to the published version of the manuscript.

Acknowledgments: The authors gratefully acknowledge financial support from the Project of National Natural Science Foundation of China (Grant No. 31870548, 51603189), the Zhejiang Provincial Collaborative Innovation Center for Bamboo Resources and High-efficiency Utilization (Grant No. 2017ZZY2-10), the Sungrant Regional Program of South Dakota State University (Grant No. A18-4000659), and the USDA National Institute of Food and Agriculture (Grant No. 1012359). 
Conflicts of Interest: The authors declare no conflict of interest.

Data Availability: The raw/processed data required to reproduce these findings can be shared via contacting to the corresponding author e-mail.

\section{References}

1. Khodadadi, M.; Malekpour, A.; Ansaritabar, M. Removal of $\mathrm{Pb}$ (II) and $\mathrm{Cu}$ (II) from aqueous solutions by $\mathrm{NaA}$ zeolite coated magnetic nanoparticles and optimization of method using experimental design. Microporous Mesoporous Mater. 2017, 248, 256-265. [CrossRef]

2. Li, N.; Bai, R.B. Highly enhanced adsorption of lead ions on chitosan granules functionalized with poly(acrylic acid). Ind. Eng. Chem. Res. 2006, 45, 7897-7904. [CrossRef]

3. Luo, X.G.; Zeng, J.; Liu, S.L.; Zhang, L.N. An effective and recyclable adsorbent for the removal of heavy metal ions from aqueous system: Magnetic chitosan/cellulose microspheres. Bioresour. Technol. 2015, 194, 403-406. [CrossRef] [PubMed]

4. Ren, H.X.; Gao, Z.M.; Wu, D.J.; Jiang, J.H.; Sun, Y.M.; Luo, C.W. Efficient Pb(II) removal using sodium alginate-carboxymethyl cellulose gel beads: Preparation, characterization, and adsorption mechanism. Carbohydr. Polym. 2016, 137, 402-409. [CrossRef]

5. Meunier, N.; Drogui, P.; Montane, C.; Hausler, R.; Mercier, G.; Blais, J.F. Comparison between electrocoagulation and chemical precipitation for metals removal from acidic soil leachate. J. Hazard. Mater. 2006, 137, 581-590. [CrossRef]

6. Dabrowski, A.; Hubicki, Z.; Podkoscielny, P.; Robens, E. Selective removal of the heavy metal ions from waters and industrial wastewaters by ion-exchange method. Chemosphere 2004, 56, 91-106. [CrossRef]

7. Blocher, C.; Dorda, J.; Mavrov, V.; Chmiel, H.; Lazaridis, N.K.; Matis, K.A. Hybrid flotation-Membrane filtration process for the removal of heavy metal ions from wastewater. Water Res. 2003, 37, 4018-4026. [CrossRef]

8. Pan, C.; Troyer, L.D.; Catalano, J.G.; Giammar, D.E. Dynamics of Chromium(VI) Removal from Drinking Water by Iron Electrocoagulation. Environ. Sci. Technol. 2016, 50, 13502-13510. [CrossRef]

9. Barrera-Diaz, C.E.; Lugo-Lugo, V.; Bilyeu, B. A review of chemical, electrochemical and biological methods for aqueous Cr(VI) reduction. J. Hazard. Mater. 2012, 223, 1-12. [CrossRef]

10. Fu, F.L.; Wang, Q. Removal of heavy metal ions from wastewaters: A review. J. Environ. Manag. 2011, 92, 407-418. [CrossRef]

11. Hua, M.; Zhang, S.J.; Pan, B.C.; Zhang, W.M.; Lv, L.; Zhang, Q.X. Heavy metal removal from water/wastewater by nanosized metal oxides: A review. J. Hazard. Mater. 2012, 211, 317-331. [CrossRef] [PubMed]

12. Meng, Y.J.; Young, T.M.; Liu, P.Z.; Contescu, C.I.; Huang, B.; Wang, S.Q. Ultralight carbon aerogel from nanocellulose as a highly selective oil absorption material. Cellu 2015, 22, 435-447. [CrossRef]

13. Pillai, S.S.; Deepa, B.; Abraham, E.; Girija, N.; Geetha, P.; Jacob, L.; Koshy, M. Biosorption of Cd(II) from aqueous solution using xanthated nano banana cellulose: Equilibrium and kinetic studies. Ecotoxicol. Environ. Saf. 2013, 98, 352-360. [CrossRef] [PubMed]

14. Zhang, M.; Li, Y.; Yang, Q.L.; Huang, L.L.; Chen, L.H.; Ni, Y.H.; Xiao, H.N. Temperature and pH responsive cellulose filament/poly (NIPAM-co-AAc) hybrids as novel adsorbent towards $\mathrm{Pb}$ (II) removal. Carbohydr. Polym. 2018, 195, 495-504. [CrossRef] [PubMed]

15. Wang, X.H.; Zheng, Y.; Wang, A.Q. Fast removal of copper ions from aqueous solution by chitosan-g-poly(acrylic acid)/attapulgite composites. J. Hazard. Mater. 2009, 168, 970-977. [CrossRef]

16. Wang, D. A critical review of cellulose-based nanomaterials for water purification in industrial processes. Cellu 2019, 26, 687-701. [CrossRef]

17. Meng, Y.J.; Wu, Q.; Young, T.M.; Huang, B.; Wang, S.Q.; Li, Y.J. Analyzing Three-Dimensional Structure and Geometrical Shape of Individual Cellulose Nanocrystal From Switchgrass. Polym. Compos. 2017, 38, 2368-2377. [CrossRef]

18. Yadav, M.; Chiu, F.-C. Cellulose nanocrystals reinforced $\mathrm{k}$-carrageenan based UV resistant transparent bionanocomposite films for sustainable packaging applications. Carbohydr. Polym. 2019, 211, 181-194. [CrossRef]

19. Kang, H.; Liu, R.; Huang, Y. Graft modification of cellulose: Methods, properties and applications. Polymer 2015, 70, A1-A16. [CrossRef] 
20. O'Connell, D.W.; Birkinshaw, C.; O'Dwyer, T.F. Heavy metal adsorbents prepared from the modification of cellulose: A review. Bioresour. Technol. 2008, 99, 6709-6724. [CrossRef]

21. Yadav, M.; Liu, Y.-K.; Chiu, F.-C. Fabrication of cellulose nanocrystal/silver/alginate bionanocomposite films with enhanced mechanical and barrier properties for food packaging application. Nanomaterials 2019, 9, 1523. [CrossRef] [PubMed]

22. Yu, X.L.; Tong, S.R.; Ge, M.F.; Wu, L.Y.; Zuo, J.C.; Cao, C.Y.; Song, W.G. Adsorption of heavy metal ions from aqueous solution by carboxylated cellulose nanocrystals. J. Environ. Sci. China 2013, 25, 933-943. [CrossRef]

23. Geng, B.; Wang, H.; Wu, S.; Ru, J.; Tong, C.; Chen, Y.; Liu, H.; Wu, S.; Liu, X. Surface-tailored nanocellulose aerogels with thiol-functional moieties for highly efficient and selective removal of $\mathrm{Hg}$ (II) ions from water. ACS Sustain. Chem. Eng. 2017, 5, 11715-11726. [CrossRef]

24. Carpenter, A.W.; de Lannoy, C.-F.; Wiesner, M.R. Cellulose nanomaterials in water treatment technologies. EnST 2015, 49, 5277-5287. [CrossRef]

25. Mohammed, N.; Grishkewich, N.; Tam, K.C. Cellulose nanomaterials: Promising sustainable nanomaterials for application in water/wastewater treatment processes. Environ. Sci. Nano 2018, 5, 623-658. [CrossRef]

26. Tang, J.T.; Song, Y.; Zhao, F.P.; Spinney, S.; Bernardes, J.D.; Tam, K.C. Compressible cellulose nanofibril (CNF) based aerogels produced via a bio-inspired strategy for heavy metal ion and dye removal. Carbohydr. Polym. 2019, 208, 404-412. [CrossRef]

27. Brito, B.S.; Pereira, F.V.; Putaux, J.-L.; Jean, B. Preparation, morphology and structure of cellulose nanocrystals from bamboo fibers. Cellu 2012, 19, 1527-1536. [CrossRef]

28. Ho, Y.S.; McKay, G. Sorption of dye from aqueous solution by peat. Chem. Eng. J. 1998, 70, 115-124. [CrossRef]

29. Ho, Y.S.; Mckay, G. Pseudo-second order model for sorption processes. Process. Biochem. 1999, 34, 451-465. [CrossRef]

30. Mall, I.D.; Srivastava, V.C.; Agarwal, N.K.; Mishra, I.M. Adsorptive removal of malachite green dye from aqueous solution by bagasse fly ash and activated carbon-kinetic study and equilibrium isotherm analyses. Colloids Surf. A Physicochem. Eng. Asp. 2005, 264, 17-28. [CrossRef]

31. Wong, Y.; Szeto, Y.; Cheung, W.; McKay, G. Equilibrium studies for acid dye adsorption onto chitosan. Langmuir 2003, 19, 7888-7894. [CrossRef]

32. Liu, X.; Yang, R.; Xu, M.; Ma, C.; Li, W.; Yin, Y.; Huang, Q.; Wu, Y.; Li, J.; Liu, S. Hydrothermal Synthesis of Cellulose Nanocrystal-Grafted-Acrylic Acid Aerogels with Superabsorbent Properties. Polymers 2018, 10, 1168. [CrossRef] [PubMed]

33. Sun, R.; Hughes, S. Fractional extraction and physico-chemical characterization of hemicelluloses and cellulose from sugar beet pulp. Carbohydr. Polym. 1998, 36, 293-299. [CrossRef]

34. Kong, W.; Chang, M.; Zhang, C.; Liu, X.; He, B.; Ren, J. Preparation of Xylan-g-/P(AA-co-AM)/GO Nanocomposite Hydrogel and its Adsorption for Heavy Metal Ions. Polymers 2019, 11, 621. [CrossRef]

35. Lin, Y.; Fang, G.G.; Deng, Y.J.; Shen, K.Z.; Wu, T.; Li, M. Highly Effective Removal of Methylene Blue Using a Chemi-Mechanical Pretreated Cellulose-based Superabsorbent Hydrogel. Bioresources 2018, 13, 8709-8722. [CrossRef]

36. Liu, L.; Liao, Q.; Xie, J.; Qian, Z.; Zhu, W.; Chen, X.; Su, X.; Meng, R.; Yao, J. Synthetic control of three-dimensional porous cellulose-based bioadsorbents: Correlation between structural feature and metal ion removal capability. Cellulose 2016, 23, 3819-3835. [CrossRef]

37. Wei, J.; Chen, Y.; Liu, H.; Du, C.; Yu, H.; Zhou, Z. Thermo-responsive and compression properties of TEMPO-oxidized cellulose nanofiber-modified PNIPAm hydrogels. Carbohydr. Polym. 2016, 147, 201-207. [CrossRef]

38. Ayawei, N.; Ebelegi, A.N.; Wankasi, D. Modelling and Interpretation of Adsorption Isotherms. J. Chem. 2017, 2017. [CrossRef]

39. Zhou, C.; Wu, Q.; Lei, T.; Negulescu, I.I. Adsorption kinetic and equilibrium studies for methylene blue dye by partially hydrolyzed polyacrylamide/cellulose nanocrystal nanocomposite hydrogels. Chem. Eng. J. 2014, 251, 17-24. [CrossRef]

40. Pang, Y.; Zeng, G.M.; Tang, L.; Zhang, Y.; Liu, Y.Y.; Lei, X.X.; Li, Z.; Zhang, J.C.; Liu, Z.F.; Xiong, Y.Q. Preparation and application of stability enhanced magnetic nanoparticles for rapid removal of $\mathrm{Cr}(\mathrm{VI})$. Chem. Eng. J. 2011, 175, 222-227. [CrossRef] 
41. Tang, H.; Zhou, W.; Zhang, L. Adsorption isotherms and kinetics studies of malachite green on chitin hydrogels. J. Hazard. Mater. 2012, 209, 218-225. [CrossRef] [PubMed]

42. Chen, C. Evaluation of equilibrium sorption isotherm equations. Open Chem. Eng. J. 2013, 7, 24-44. [CrossRef]

43. Liu, J.; Ma, Y.; Xu, T.; Shao, G. Preparation of zwitterionic hybrid polymer and its application for the removal of heavy metal ions from water. J. Hazard. Mater. 2010, 178, 1021-1029. [CrossRef] [PubMed]

44. Lin, Y.; Fang, G.G.; Deng, Y.J.; Shen, K.Z.; Huang, C.; Wu, T. A pH-sensitive Xylan-based Superabsorbent Hydrogel for the Removal of Methylene Blue from Water. Bioresources 2019, 14, 5573-5585.

45. Chen, B.; Zheng, Q.; Zhu, J.; Li, J.; Cai, Z.; Chen, L.; Gong, S. Mechanically strong fully biobased anisotropic cellulose aerogels. RSC Adv. 2016, 6, 96518-96526. [CrossRef]

46. Putro, J.N.; Santoso, S.P.; Ismadji, S.; Ju, Y.-H. Investigation of heavy metal adsorption in binary system by nanocrystalline cellulose-Bentonite nanocomposite: Improvement on extended Langmuir isotherm model. Microporous Mesoporous Mater. 2017, 246, 166-177. [CrossRef]

47. Xu, Q.; Wang, Y.; Jin, L.; Wang, Y.; Qin, M. Adsorption of $\mathrm{Cu}(\mathrm{II}), \mathrm{Pb}(\mathrm{II})$ and $\mathrm{Cr}$ (VI) from aqueous solutions using black wattle tannin-immobilized nanocellulose. J. Hazard. Mater. 2017, 339, 91-99. [CrossRef]

(C) 2020 by the authors. Licensee MDPI, Basel, Switzerland. This article is an open access article distributed under the terms and conditions of the Creative Commons Attribution (CC BY) license (http://creativecommons.org/licenses/by/4.0/). 